\title{
CRISIS DEL MEDIO AMBIENTE Y DESARROLLO. UNA PERSPECTIVA DE CLASES
}

\author{
Eliane Tomiasi Paulino \\ Universidade Estadual de Londrina \\ eliane.tomiasi@uel.br
}

\begin{abstract}
Entre las incertidumbres y angustias de nuestro tiempo, una de las más evidentes es la crisis ambiental, cuya expresión debe emplearse con precaución, pues puede sugerir la presencia de un fenómeno pasajero, pero no es el caso. La crisis es permanente porque consustancial al capitalismo, ya que resulta de la lógica de acumulación que convierte a los recursos naturales en bienes comercializables, necesariamente en una escala ascendente. Como la voracidad del capital se manifiesta con una intensidad desproporcionada en la periferia, amenazando poblaciones y ecosistemas, es necesario pensar el problema desde dos dimensiones: geopolítica y clases sociales, puesto que en esta combinación se revelan las fragilidades discursivas y las brechas para el enfrentamiento.
\end{abstract}

L a mundialización del capital ha traído no sólo la redefinición de los términos negociables entre capital y trabajo, en detrimento del último componente, sino también el debilitamiento de los ecosistemas a escala planetaria, salvo los diferentes gradientes de los impactos en gran medida resultantes del valor de cambio inherente a los recursos existentes y su ocurrencia de acuerdo con la posición geográfica y su lugar en la división territorial del trabajo. Todo esto es absolutamente coherente con un modo de producción en el cual el centro es la acumulación ampliada del capital, prevaleciendo el imperativo de la transformación cada vez más acelerada de los recursos naturales en mercancías por medio de la fuerza creativa que sólo es posible en el trabajo humano.

No por coincidencia, los principios incluidos en los planes de desarrollo gestados dentro de las organizaciones multilaterales son repetidos en el nivel discursivo por los gobiernos en las instancias federal, estatal y, hasta, municipal. En general, la atención se concentra en dos frentes de acción, el bienestar social y la sostenibilidad ambiental. Esta matriz discursiva muestra que hoy éstas son las más destacadas expresiones de las contradicciones generadas en el núcleo de las relaciones de producción, ya que la asociación entre el trabajo y los bienes libres de la naturaleza es la única fuente generadora de los valores de uso que sostienen a la sociedad. Estos dos pilares no son únicamente del presente, sino también del devenir, y están siendo despreciados en el acuerdo societario establecido en nombre de la libertad, la fraternidad y la igualdad, al punto de tornar inviable un horizonte de larga duración para la civilización.

Lo que se refiere a la gestión territorial, la difícil conciliación entre las propuestas y sus ejecuciones, revela que el Estado nacional es la instancia primordial de mediación, y eso es válido tanto para sus acciones internas como para las relaciones internacionales. Sin embargo, lejos de posicionarse en un plan que permite el celo del bien común, está apropiado por las fuerzas que coyuntural o estructuralmente son hegemónicas en cada país y están ordenadas desde una perspectiva de clase y su respectivo lugar en la esfera de la producción global. La mejor manera de reconocerlas fue enseñada por Marx: ${ }^{1}$ basta identificar la fuente de los ingresos de los individuos; puede venir de su trabajo transferido a otro mediante un salario u obtenido en la operación inversa, o sea, cuando resulta de la compra ajena de trabajo; y, por último, en los casos en que provienen de la condición social extraordinaria conferida por la propiedad privada de la tierra, sea urbana o rural, que garantiza a sus detentadores el derecho de cobro de la renta, el tributo automático que toda la sociedad, sin darse cuenta, paga a los propietarios para tener el derecho de existir, ya que necesita alimentarse, vestirse y vivir, y todo esto supone la tierra que está cercada para pocos.

Es cierto que estas posiciones no son mutuamente excluyentes: aunque existen contradicciones irreconciliables, puede haber una convergencia parcial de intereses e incluso algunas alianzas entre una y otra clase. En general, lo que conviene a los vendedores de la fuerza de trabajo va en contra de los intereses de los compradores de la misma. El mejor ejemplo son las estrategias comunes con vistas a la extracción de la plusvalía que se observa comúnmente entre los propietarios capitalistas de la tierra y los miembros de la burguesía urbana, como es el caso de industriales, banqueros y comerciantes, que además pueden constituir una única persona con negocios agrícolas y urbanos como los mencionados y, eventualmente, otros de carácter capitalista. Por definición, se alinean en la confrontación con los trabajadores y sus luchas para neutralizar o reducir este saqueo contra sí mismo. 
Esto revela que en la actualidad existen dos clases que componen el bloque hegemónico de la sociedad capitalista: los capitalistas dueños de tierras y los capitalistas propietarios de los demás medios de producción. Entre ellos se dividen el excedente de la riqueza. Cabe advertir que no se habla de la riqueza sobrante, sino de la riqueza extraída a expensas de una degeneración de las condiciones mínimas de existencia de los productores directos, sin hablar de la riqueza explotada con antelación a las generaciones futuras, cuya herencia será enormes pasivos ambientales, una deuda que inevitablemente están obligadas a liquidar, sea con gasto suplementario de energía vital - más trabajo todavía-, o sea con la vida en el sentido estricto, dónde y cuándo se reducirá por la ausencia del mínimo requerido, por ejemplo, el agua potable y los alimentos.

La coalición de clases en los términos descritos ha sido capaz de poner en segundo plano algunas diferencias intrínsecas, tales como la permanencia del tributo indistinto que es la renta de la tierra. Esta anomalía sólo resistió al modo de producción capitalista en vista de la necesidad que tuvo la burguesía de asegurar la legitimidad de los derechos de propiedad, el principio que está en la raíz de la separación del trabajador de la utilización autónoma de su energía creativa y el disfrute de sus resultados.

Así pues, en común o por referéndum, todo y cualquier mecanismo institucional que puede ser utilizado para perpetuar su supremacía lo será y toda oposición será restringida. Por eso, la represión social con el uso de la violencia es la última estrategia, cuando no hay más espacio para la mediación, ya que, como advirtió Hannha Arendt ${ }^{2}$, una evidencia de la pérdida de legitimidad en el ejercicio del poder es el uso de la fuerza.

Por lo tanto, para que prevalezca el imperativo de la acumulación ampliada del capital, toda propuesta de gestión transformadora será rechazada o adaptada, convirtiéndose en la mejor de las hipótesis en acciones paliativas que no pueden modificar los procesos estructurales, pues ésos están constituidos por los engranajes voraces de la acumulación ampliada, cuya fuerza destructiva no admite desdén, como tan lúcidamente explicó Armando Bartra ${ }^{3}$.

Sin embargo, no se trata de proponer la problemática en términos de la concepción estructuralista, como si no hubiera fuerzas disidentes - porque hasta los enfrentamientos sociales son dignos de nota-, no obstante que aún son desproporcionales a lo requerido para la superación de tan poderosa orden. Hay que destacar también las evidentes contradicciones de la compleja dinámica del ejercicio del poder que conforma la etapa contemporánea del capitalismo, en la que se enfrentan la resistencia y el combate contra la adhesión a los dictados del capital.

Aun con el reconocimiento de su supremacía bajo las asimétricas relaciones trabadas en el seno de la sociedad en el proceso de producción material y reproducción social, hay que escapar de la trampa abstracta que confunde hegemonía con homogeneidad, pues es precisamente en el desacuerdo que es posible construir los medios para su superación.

Ésta síntesis se materializa en la territorialización distintiva con que se presentan los países bajo sus composiciones internas de fuerzas, siendo más favorable para comprender los dilemas y las perspectivas del momento actual, en lugar de la oposición entre países ricos y pobres, desarrollados y subdesarrollados, pues en el fondo lo fundamental de las contradicciones es lo mismo, variando tan sólo su intensidad, en vista de la mayor o menor capacidad demostrada por los trabajadores y campesinos de oponerse al proyecto estructural de acumulación, por medio de sus pautas de reivindicación y de sus estrategias alternativas de sobrevivencia. Las múltiples dimensiones del poder en movimiento no sólo configuran distintos territorios, como revela el gradiente de fuerzas de cada una de las clases, su ámbito de actuación es, por excelencia, el territorio nacional.

No se equivocó Wanderley Messias da Costa ${ }^{4}$ al afirmar que los Estados nacionales son solamente los límites territoriales impuestos por los grupos hegemónicos locales, como una forma de asegurar para sí una base de recursos considerados esenciales para su perpetuación. Entonces, por más fuera de moda que pueda parecer, la develación de la composición de clases es esencial para entender los dilemas que ahora se colocan en términos ambientales y sociales. Del mismo modo, es una herramienta analítica que permite cuestionar algunas teorías muy difundidas sobre la globalización, en particular la que prescribe la impotencia de los Estados naciones frente al poder de las corporaciones transnacionales y su incapacidad de regir los procesos que aún sean proyectados desde afuera tienen amplios reflejos territoriales internos.

No es sensato ignorar la notable fluidez territorial de ellas, fruto de un aparato de gestión cuyas condiciones técnicas y económicas llegan a ser superiores a la de algunos países, pero tomarla como si fuera inevitable es lo mismo que refrendar indirectamente los tratados, acuerdos, programas y concesiones nefastos a los pueblos y su ambiente.

Así, en nombre del desarrollo improbable, se potencializan las vulnerabilidades que hoy afectan a una parte importante de la humanidad, cuyas privaciones severas no tienen cualquier justificación en el escenario técnico productivo, solamente en las interdicciones a los bienes vitales de los cuales se nutren los capitalistas.

El hecho es que los Estados nacionales disponen de la prerrogativa exclusiva de manejar la base de recursos atrapados dentro de sus fronteras. En la orden neoliberal, lo hacen a través de la imposición de normas legales 
para regular la acción privada, los marcos regulatorios que están en el ámago de las disputas que se expresan en las agendas de los partidos políticos, de las asociaciones clasistas, de los movimientos sociales, además los que se definen lejos de la política visible a los ciudadanos, por detrás de las escenas del Estado.

En esta confrontación, la trascendencia de clase en relación con las fronteras nacionales es explícita: la acción de grupos extranjeros en suelo patrio depende de la licencia del Estado y cuando éste la concede, incluso en detrimento de los intereses nacionales, es porque conviene a los intereses de los que internamente mantienen la hegemonía, luego gobiernan el país, y esto, obviamente, va más allá de las posiciones mantenidas en la estructura político-administrativa del aparato estatal. Las concesiones mineras, la explotación de los recursos hídricos y grandes extensiones de bosques o tierras agrícolas, en perjuicio de la población local, son los mejores ejemplos en la actualidad. Ésta es la alineación que no se define por la pertenencia territorial, la nacionalidad, sino lo que proviene de la posición de clase.

Aunque en estos acuerdos prevalecen mecanismos de intercambio desigual, en que los bienes primarios son devaluados hasta ser sometidos a los procesos de agregación de valor que ahora están bajo el control de un pequeño número de corporaciones transnacionales, la élite de la periferia también se complace. Por lo tanto, es posible entender por qué son precisamente los países periféricos ricos en recursos que muestran los mayores índices de desigualdad social. Otro buen indicador de ese intrincado juego de poder es el celo con que los gobiernos de los países sede de dichas empresas los protegen. Además, estas estrategias son nada más que la síntesis de la diplomacia política internacional.

En tiempos del apetito voraz por tierra, agua, árboles, minerales y una lista innumerable de bienes que revelan la privatización de la naturaleza, estas consideraciones son importantes para delinear el enfoque de la lucha social, debido a que el gigante tiene pies de barro. Por lo tanto, tenemos que escapar de la encerrona sutil de la inmovilidad que emana de las tesis que ignoran el contenido de clase oculto en las disputas sobre los recursos naturales y sobre el trabajo, los pilares de la producción en cualquier escala, desde un municipio hasta un continente. En su lugar, tenemos que explicar lo concreto de los conceptos a través de la identificación de su contenido:

¿Qué es la globalización, sino una etapa de circulación de las mercancías según los términos de cambio, sino establecidos, seguramente ratificados por cada Estado-nación? ¿Qué es la crisis ambiental, sino una evidencia de la conversión de los activos gratuitos en objetos con valor de cambio, a una tasa de extracción superior a la capacidad regenerativa de la naturaleza? Además, según una lógica incompatible con el usufructo que el concepto de bienes naturales contiene, y que al ser convertida en mercancía sujeta a compra, queda disponible a sólo unos pocos. ¿Qué es la geopolítica, sino el juego diplomático internacional emprendido por los gobiernos nacionales en convergencia estricta con los intereses hegemónicos internos?

Tales contenidos han permeado el concepto de clases, la evidencia que a pesar de la compleja dinámica de funcionamiento del modo de producción capitalista, en esencia no hay nada nuevo a lo que $\mathrm{Marx}^{5}$ señaló para identificar los elementos clave del proceso general de producción, que se refiere al intercambio de los seres humanos entre sí y con la naturaleza para la satisfacción de necesidades vitales, sean ellas reales o ficticias. Esto culmina en el trípode elemental: el trabajo que subsume la creación de valor, la tierra, este recurso natural que constituye la base material de la existencia y, por último, el capital, expresado por los medios de producción creados e impulsados por el trabajo humano con vista a la apropiación de la plusvalía, el valor generado en el proceso de producción que no vuelve a sus creadores.

La profundidad de la crisis social y ambiental es que los bienes inalienables son deteriorados aunque el orden hegemónico nos hace creer que son reproducibles e inextinguibles. Un devenir posible requiere otro proyecto societario, el cual no va venir sino a través de un amplio reposicionamiento ante la noción de desarrollo, capaz de romper con la representación fabril y lo fetiche de la producción mágica de todo lo que hay alrededor. Se trata de construir un concepto de sostenibilidad donde la parsimonia esté en primer lugar, la cual es incompatible con la lógica de la acumulación ampliada. Como se ha visto, al mismo tiempo que ella encadena algunos en el imperativo del consumo desenfrenado, absorbe la mayor parte del excedente que le va alimentar.

\footnotetext{
Referencias

${ }^{1}$ Marx, Karl (1974), O capital, livro 3, vol. 6. Río de Janeiro, Civilização Brasileira.

${ }^{2}$ Arrendt, Hannah (2009), Sobre a violencia, Río de Janeiro, Civilizacao Brasileira.

${ }^{3}$ Bartra, Armando (2008), El hombre de hierro. Los límites socialies y naturales del capital, México, UNAM-ITACA. ${ }^{4}$ Costa, Wanderley Messias (2008), Geografia política e geopolítica. 2. Brasil, EDUSP.

${ }^{5}$ Marx, Karl (1974), op. cit.
} 